\title{
Bases vigotskianas da Atividade Orientadora de Ensino
}

\author{
Vygotskian bases of Teaching-Orienteering Activity
}

Débora Cristina Piotto ${ }^{1}$

\begin{abstract}
RESUMO
O objetivo do artigo é discutir algumas bases vigotskianas que apoiam teórica e metodologicamente a Atividade Orientadora de Ensino. Para isso, inicialmente, o texto apresenta uma breve definição dessa Atividade. Em seguida, discorre sobre ideias vigotskianas como formação de conceitos e relação entre pensamento e fala. Como considerações finais, o artigo aponta a potencialidade educativa desse modo geral de organização do ensino.
\end{abstract}

Palavras-chave: Teoria Histórico-cultural. Organização ensino. Vigotski. Atividade Orientadora de Ensino.

\begin{abstract}
The aim of the article is to discuss some Vigotskian bases that theoretically and methodologically support the TeachingOrienteering Activity. For this, initially, the text presents a brief definition of this Activity. Then, it discusses some Vigotskian ideas such as concept formation and the relationship between thought and speech. As final considerations, the article points out to the educational potential of this general way of organizing teaching.
\end{abstract}

Key-words: Cultural-historical theory. Teaching organizing. Vygotsky. TeachingOrienteering Activity.

\section{Introdução}

O objetivo do presente artigo é discutir algumas bases vigotskianas que apoiam teórica e metodologicamente a Atividade Orientadora de Ensino, objeto deste Dossiê.

Para isso, realizamos um levantamento de textos mais recentes que tratassem de forma mais específica dessa Atividade. Outro critério utilizado para a escolha dos textos, que embasaram a análise que será aqui exposta, diz respeito à acessibilidade. Assim, foram utilizados, preferencialmente, artigos e capítulos de livros de fácil acesso para aqueles que tiverem interesse em aprofundar-se no tema. Importante mencionar que este levantamento não teve a intenção de ser exaustivo nem sistemático, objetivando apenas fornecer ao leitor uma descrição dos aspectos mais centrais e relevantes que caracterizam a Atividade

\footnotetext{
${ }_{1}^{1}$ Programa de Pós-graduação em Educação, Faculdade de Filosofia, Ciências e Letras de Ribeirão Preto / USP, Brasil. Orcid: https://orcid.org/0000-0002-9349-0218. E-mail: dcpiotto@usp.br.
} 
Orientadora de Ensino (doravante também denominada AOE). Assim, a partir dos textos selecionados, foi feita uma breve caracterização da AOE.

E em consonância com o tipo de levantamento feito, também esta caracterização não objetivou realizar uma sistematização e um resgate histórico da construção e da proposição da AOE. Originada a partir da tese de doutoramento de Manoel Oriosvaldo de Moura (MOURA, 1992), professor titular aposentado da Faculdade de Educação da Universidade de São Paulo, a ideia da Atividade Orientadora de Ensino tem sido objeto de pesquisa, ensino e extensão de muitos trabalhos, resultado em um grande volume de publicações, muitas dissertações de mestrado e teses doutorado e constituído uma importante fonte heurística para já três gerações de pesquisadores. Nesse sentido, o presente texto não tem por objetivo realizar um inventário sistemático de toda essa produção, nem isso seria possível no escopo desse artigo. Não obstante, importa destacar que as questões que serão aqui abordadas trazem consigo as contribuições desses trabalhos, que embora não possam ser todas nomeadas, marcam o modo coletivo de trabalho do grupo de pesquisa que se formou a partir da pesquisa pioneira de Moura (1992) - o Grupo de Estudos e Pesquisa sobre Atividade Pedagógica (GEPAPe).

Além do levantamento, para a discussão de ideias vigotskianas que apoiam a Atividade Orientadora de Ensino, utilizamos algumas obras de Lev S. Vigotski. Valemo-nos, principalmente, do último livro escrito pelo autor e publicado em 1934, após sua morte. E em função também do critério de facilidade de acesso, recorremos preferencialmente à publicação brasileira "A construção do pensamento e da linguagem" (VIGOTSKI, 2001) traduzida diretamente do livro russo "Michlienie i rietch" (Pensamento e fala). Contudo, em função de problemas relacionados a essa tradução, para algumas citações diretas de Vigotski, e visando maior clareza e rigor quanto às ideias do autor, recorremos à tradução argentina Pensamiento y habla (VIGOTSKI, 2007), também feita diretamente do original em russo, por considerarmos que algumas passagens estão mais bem esclarecidas nessa obra ${ }^{2}$.

Para a discussão de bases vigotskianas da AOE utilizamos também as ideias discutidas no livro "As sete aulas de L. S. Vigotski” (VIGOTSKI, 2018),

2 A respeito dos problemas da tradução brasileira ver, por exemplo, Prestes e Tunes (2012). 
publicação de textos inéditos do autor lançada no Brasil em 2018 e também traduzida do russo. Contudo, novamente para a citação direta de Vigotski, utilizamos outra tradução, a saber "A Quarta aula: a questão do meio na pedologia" (VIGOTSKI, 2010), por avaliarmos que ela apresentava mais claramente as ideias do autor no trecho usado para a análise empreendida ${ }^{3}$.

A partir desses procedimentos, realizamos a análise que será apresentada no presente texto e está organizada em quatro partes. Inicialmente, apresentaremos uma breve definição da Atividade Orientadora de Ensino. Em seguida, discutiremos algumas ideias vigotskianas sobre a formação de conceitos e a relação entre pensamento e fala. E, por fim, teceremos as considerações finais.

\section{Atividade Orientadora de Ensino: uma breve caracterização}

Partindo da compreensão da atividade pedagógica como unidade entre ensino e aprendizagem, ou, mais especificamente, entre a atividade de ensino, realizada pelo professor, e a atividade de aprendizagem que tem lugar na criança ou estudante, a Atividade Orientadora de Ensino (AOE) constitui uma proposta de um modo geral de organização do ensino a partir de contribuições da Teoria Histórico-cultural (MOURA et al., 2010; MOURA; ARAUJO; SERRÃO, 2018). Em outras palavras, a AOE é uma forma geral de organização da atividade pedagógica que objetiva promover a aprendizagem e, assim, fazer avançar o desenvolvimento humano (MOURA; SFORNI; LOPES, 2017).

Nesse sentido, a Atividade Orientadora de Ensino é, ao mesmo tempo, um instrumento do professor para compreender e realizar seu objeto de trabalho - o ensino de conceitos - e também é um instrumento do estudante que age rumo à apropriação desses conceitos (MOURA, ARAUJO, SERRÃO, 2018). Ou, como afirmam Moura et al. (2010), a AOE é uma base teórico-metodológica de desenvolvimento para quem ensina e para quem aprende.

Entendendo a atividade pedagógica como uma atividade humana, a AOE está estruturada a partir da concepção de atividade proposta por Leontiev (1978). Nesse sentido, ela deve ser motivada por uma necessidade, cuja

\footnotetext{
${ }^{3}$ Dentre as sete aulas publicadas em 2018, esta era a única que já havia sido traduzida no Brasil. Outra tradução desse mesmo texto também pode ser encontrada em Vigotski (2017).
} 
satisfação requer ações e operações intencionalmente planejadas para a concretização do objetivo inicial. Assim, a Atividade Orientadora de Ensino tem um motivo, tem por finalidade a satisfação de uma necessidade e tem ações e operações que possibilitam colocar em movimento a apropriação de conhecimento (MOURA; ARAUJO, 2018). Nas palavras de Moura e Araújo (2018), na AOE: “... o ensino, entendido como atividade, deve ser organizado de modo que sujeitos ajam motivados por uma necessidade, cuja satisfação requer instrumento e modo de ação para objetivá-la.” (p. 212).

Baseada na ideia marxista de que todo conhecimento é resultado de trabalho humano, a Atividade Orientadora de Ensino busca recriar situações que, na história da humanidade, geraram uma necessidade real cujo atendimento resultou na produção de determinado conceito. Dessa forma, a AOE coloca o estudante em uma situação que, sinteticamente, e em relação ao essencial, assemelha-se a um problema com o qual a humanidade se deparou em seu processo histórico de desenvolvimento e que originou um conceito.

Nessa direção, a Atividade Orientadora de Ensino é composta por "situações desencadeadoras de aprendizagem”, como jogo pedagógico, situações emergentes do cotidiano e história virtual do conceito (MOURA; ARAUJO; SERRÃO, 2018) que possuem, em comum, o fato de conter em si um problema mobilizador oriundo de necessidades de ordem prática que gerou o desenvolvimento de um determinado conceito na história da humanidade. A situação desencadeadora de aprendizagem que compõe a AOE objetiva colocar o estudante em uma "tensão criativa", de modo semelhante ao que os seres humanos vivenciaram ao terem de resolver problemas autênticos gerados por necessidades práticas ao longo de seu processo histórico, procurando, desse modo, (re)criar meios de resolução de problemas a partir de situações com as quais, guardadas as proporções, a humanidade já tenha se deparado em seu processo histórico (MOURA, ARAUJO, SERRÃO, 2018). Ou, como afirmam Moura e Araújo (2018):

A 'atividade orientadora de ensino' organiza situações desencadeadoras de aprendizagem, ações nas quais as práticas sociais da humanidade, objetivadas na forma de conceitos científicos, podem ser subjetivadas. (p. 212). 
Exemplo de uma situação desencadeadora é descrita e analisada por Munhoz et al. (no prelo). A situação foi organizada a partir dos princípios teóricometodológicos da AOE e desenvolvida por uma professora que estava estudando tais princípios em seu processo de formação. A Atividade foi realizada com um grupo de crianças de cinco anos que frequentavam uma pré-escola. Uma história virtual ("A viagem de Ulisses") foi elaborada a partir do livro "A Odisseia", na adaptação de Ruth Rocha e conta que o herói grego Ulisses foi capturado por uma feiticeira, que o mantém refém na ilha e o destitui de todos os seus conhecimentos matemáticos. Além disso, a feiticeira lhe atribuiu a tarefa de cuidar dos animais da ilha, de modo que nenhum se perdesse. Por meio de uma carta, Ulisses pede ajuda às crianças sobre como poderia fazer isso sem saber contar. As crianças mobilizam-se com a necessidade de ajudar o herói e, por meio de uma cartaresposta, propõem que ele controle a quantidade de animais por meio da correspondência um a um, utilizando uma pequena pedra para cada animal. $\mathrm{Na}$ sequência, o herói agradece a ajuda e coloca um novo problema. A quantidade de animais aumentou muito, não sendo mais possível fazer o controle usando a correspondência de uma pedra para cada animal. Então, Ulisses pergunta para as crianças como ele poderia controlar todos os animais, garantir que nenhum se perdesse, utilizando uma pequena quantidade de pedras. No desenvolvimento da atividade, uma criança diz: "já sei, uma pedrinha que vale 3 ... ou 4 ou 5!".

$\mathrm{Na}$ situação desencadeadora de aprendizagem analisada por Munhoz et al. (no prelo), o problema apresentado para as crianças coloca-as diante de uma situação semelhante à vivida pela humanidade em seu processo histórico de criação do conceito de número: controlar quantidades cada vez maiores com o menor número possível de objetos-signos. E a fala da criança evidencia o movimento de seu pensamento em direção à resolução do problema humano sintetizado e mediado pelo conceito um que vale muitos (MUNHOZ et al., no prelo) ${ }^{4}$.

\footnotetext{
4 Outros exemplos de situações desencadeadoras de aprendizagem também podem ser encontrados em Rosa; Moraes; Cedro (2010), Moura; Sforni; Lopes (2017), Moura; Araújo; Serrão (2018), Nascimento (2018); Panossian et al. (2018), Rosa; Matos (2018), Moraes; Lazaretti; Arrais (2019), entre outras publicações.
} 
Após esta breve apresentação da Atividade Orientadora de Ensino, passaremos, na sequência, a discutir algumas ideias vigotskianas em que essa forma de organização de ensino está baseada.

\section{Bases vigotskianas}

Discutindo o processo por meio do qual o desenvolvimento do pensamento conceitual ocorre, Vigotski opõe-se à ideia associacionista de que o conceito vem do concreto, dos objetos e de que se trata de simples associação entre termos.

Analisando os resultados da investigação realizada por Ach, Vigotski (2001) afirma que associações verbais entre símbolos e objetos não eram suficientes para a formação de conceitos. Baseado nessa investigação, Vigotski afirma também que aprender palavras e associá-las com objetos não conduz por si só à formação de conceitos. Ele discute, ainda, que os conceitos se formam segundo um processo orientado para um determinado fim e composto por uma série de operações cuja função é servir de meios para resolver a tarefa principal, de modo que essa tarefa não possa ser resolvida a não ser pela formação de conceitos (VIGOTSKI, 2001).

Em suas palavras:

No método de Ach em que se consideram as condições funcionais de formação do conceito] O conceito é tomado em relação com uma determinada tarefa ou necessidade que surge no pensamento, em relação com a compreensão ou a comunicação, em relação com a execução de alguma tarefa, ou instrução, cuja realização resulta impossível sem a formação do conceito. (VYGOTSKI, 2001, p. 121).

Segundo Vigotski (2001), Ach denunciou o erro do ponto de vista associativo sobre o processo de formação de conceitos, explicando a importância de se considerar a função para a compreensão do conceito. Ele também salientou o fato de que o conceito apenas pode surgir e se formar como resposta a uma necessidade concreta "no curso de alguma atividade dirigida a alcançar um fim determinado de sentido, orientado para um objetivo determinado ou à resolução de uma tarefa concreta." (VYGOTSKI, 2011, p. 126).

Com base na investigação de Ach e também de Rimat, e contrariamente ao associacionismo, Vigotski discute como o conceito resulta de uma conquista, de 
uma ação do pensamento, sendo este um processo de caráter produtivo. Para ele, o conceito possui uma função e uma das questões mais importantes para a sua formação é a relação com a realidade. O conceito surge como resultado do pensamento. Os conceitos formam-se sempre no processo de solução de algum problema; apenas como resultado da solução desse problema é que podem surgir os conceitos, reforça o autor.

Contudo, embora Vigotski (2001) valha-se das investigações conduzidas por aqueles autores para afirmar sua compreensão acerca do processo de formação dos conceitos, também tece algumas críticas ao método por eles utilizado. Uma delas refere-se ao fato de Ach e Rimat acreditarem que a tarefa proposta encerraria em si mesma a solução para o problema que ela propõe (VIGOTSKI, 2001). Além disso, o método não explicaria o processo genético da formação do conceito, não conseguindo revelar a sua natureza genética, funcional e estrutural. De acordo com Vigotski, é preciso explicar como se desenvolvem as formas de pensamento, bem como qual é a determinação dinâmico causal da formação de conceitos. E é isso o que ele se propõe a fazer no livro "Pensamento e fala" nos dois capítulos subsequentes ao capítulo cinco em que aborda os experimentos desses pesquisadores.

Após analisar o processo de desenvolvimento do pensamento conceitual, discutindo o pensamento sincrético e o pensamento por complexos, Vigotski (2001) afirma que os experimentos que ele e seu grupo de colaboradores conduziram mostram como das imagens e conexões sincréticas do pensamento por complexos, dos conceitos potenciais, e sobre a base do emprego da palavra como meio de formação do conceito, surge a singular estrutura significativa a que se pode chamar genuinamente de conceito. E fazendo uma síntese da discussão, afirma o autor:

Como dissemos, o conceito surge durante uma operação intelectual; não é o jogo de associações o que conduz à construção do conceito. Em sua formação intervêm todas as funções intelectuais de uma combinação original, cujo fator central é o uso funcional da palavra como meio de orientação deliberada da atenção, da abstração, da seleção de atributos e de sua síntese e simbolização com ajuda do signo. (VYGOTSKI, 2001, p. 176) 
A relação com a palavra é um dos principais traços distintivos do processo de formação de conceitos. Para Vigotski (2001), a palavra possui um papel central na formação dos conceitos. Ainda segundo o autor:

[...] o conceito é impossível sem palavras, o pensamento em conceitos é impossível fora do pensamento verbal; em todo esse processo, o momento central, que tem todos os fundamentos para ser considerado causa decorrente do amadurecimento de conceitos, é o emprego específico da palavra, o emprego funcional do signo como meio de formação de conceitos. (p. 132)

Em síntese, Vigotski opõe-se ao associacionismo mostrando que o conceito não vem do concreto, dos objetos, sendo uma acumulação deles ou estando neles depositados, mas, ao contrário: o conceito é um movimento, uma conquista, uma ação do pensamento. Além disso, o autor destaca também o papel da palavra nesse processo.

E é em função da relevância da palavra no processo de desenvolvimento dos conceitos que trataremos mais detalhadamente dela a seguir.

\section{A palavra e o processo de formação do conceito}

Tendo como objetivo último a formulação de uma nova Psicologia, a partir do método materialista dialético, Vigotski (2001) e seus colaboradores empreendem estudos sobre a consciência humana, objetivando chegar a uma explicação que contemplasse o desenvolvimento humano em sua complexidade e totalidade.

A consciência, segundo o autor, embora envolva o pensamento, é mais ampla, incluindo-o, mas não se reduzindo a ele. Ao tratar da necessidade de se considerar a consciência para se compreender o pensamento, o autor aponta para essa definição mais ampla, que integra aspectos relacionados a motivos e emoções na consciência:

O pensamento não nasce de si mesmo nem de outros pensamentos, mas da esfera motivacional de nossa consciência, que abarca nossas inclinações e nossas necessidades, nossos interesses e impulsos, nossos afetos e emoções. Por trás de cada pensamento há uma tendência afetivo-volitiva. Só ela tem a resposta ao último porquê na análise do processo de pensar. (VYGOTSKI, 2001, p. 342).

Em síntese, segundo Toassa (2016), para Vigotski por trás da consciência estaria a própria vida. 
Com o objetivo de explicar a consciência humana, Vigotski dedica-se ao estudo da relação entre pensamento e fala, que constitui, para ele, a chave para se compreendê-la ${ }^{5}$.

A relação entre pensamento e fala é, para Vigotski, algo complexo e essencialmente dialético. Para discutir essa relação, o autor trata também de outros dois tipos de fala: a fala interna (para si) e a externa (para os outros) (VIGOTSKI, 2007). A discussão sobre essas duas falas parece-nos traduzir a compreensão vigotskiana acerca da relação entre exterior e interior, entre social e individual, bem como da direção e explicação do desenvolvimento humano.

Sendo a relação entre pensamento e fala dialética e dinâmica, Vigotski (2007, p. 503, tradução nossa) afirma que, se a fala externa é um processo de transformação do pensamento em palavras, de materialização e objetivação do pensamento, na fala interna:

[...] observamos um processo em sentido inverso, um processo que vai de fora para dentro, um processo de evaporação de fala em pensamento. Mas a fala não desaparece de maneira nenhuma em sua forma interna. A consciência não desaparece em absoluto nem se esfumaça no espírito puro. Ao contrário, a fala interna segue sendo fala, isto é, pensamento vinculado com a palavra. Mas, se na fala externa o pensamento se encarna na palavra, na fala interna esta palavra morre ao dar à luz ao pensamento. [...] A fala interna é dinâmica, instável, variável, e oscila entre os dois pólos extremos que temos estudado, mais formados e estáveis, do pensamento discursivo: entre a palavra e o pensamento.

Pensamento e fala interna, portanto, não são coincidentes, mas estão correlacionados. Ademais, pela discussão empreendida por Vigotski, pode-se depreender que, quando esse autor trata de pensamento, ele também tem em mente algo que vai além da dimensão cognitiva, algo mais amplo, que envolve inclusive a questão do sentimento, da emoção. Tratando da "inexpressividade" do

\footnotetext{
${ }_{5}^{5}$ Muito embora no Brasil estejamos mais habituados a usar a expressão "relação pensamentolinguagem", talvez por conta da tradução de obras de Vigotski que foram publicadas no Brasil sob os títulos "Pensamento e linguagem" e, posteriormente, "A construção do pensamento e da linguagem", no presente trabalho, utilizaremos a expressão "pensamento e fala" por considerar que ela traduz melhor a ideia do autor, já que Vigotski está se referindo a um código linguístico desenvolvido pela humanidade, ou seja, à fala ou à língua. Pensamiento y habla ("Pensamento e fala") é o título da tradução argentina da obra de Vigotski (2007), que também é utilizada neste texto. Segundo Prestes e Tunes (2012), esta tradução inaugurou oficialmente uma mudança radical ao traduzir "rietch" como fala e não como linguagem.
} 
pensamento e da imperfeição da palavra, Vigotski cita os versos do autor russo Tiuchev: "Como exprimir-se um coração...” ou "Ah, se a alma pudesse expressarse sem palavras!”. Ele afirma ainda que o pensamento não coincide diretamente com a sua expressão verbalizada e que pode ser comparado a uma "nuvem espessa que descarrega uma chuva de palavras" (VIGOTSKI, 2007, p. 507, tradução nossa). Ou seja, pensamento e fala não coincidem; são processos distintos, mas numa relação complexa, dinâmica e dialética. O pensamento, que contempla também aspectos afetivos, não coincide nem se esgota na fala, tampouco consegue expressar-se total, completa ou fielmente nela. Em contrapartida, sem a fala, sem a palavra, ele não tem forma. De acordo com Vigotski (2007, p. 507, tradução nossa): "O pensamento não se reflete na palavra, mas se realiza nesta". Tal ideia é tão importante para a compreensão do autor sobre a relação entre pensamento e fala que ele a repete três vezes no texto "Pensamento e palavra" (último capítulo do livro Pensamento e fala $)$. A epígrafe desse texto também expressa tal compreensão: "Esqueci a palavra que ia dizer, e meu pensamento, privado de sua substância, volta ao reino das sombras.”7. Isto é, para Vigotski, a palavra é a base material do pensamento; a palavra não coincide com o pensamento (nem o contrário), mas é a sua materialidade:

Percebemos que a relação entre pensamento e palavra é um processo vivo de nascimento do pensamento na palavra. Palavra privada de pensamento é, antes de mais nada, palavra morta. [...] Mas o pensamento que não se materializa na palavra continua como uma sombra... (VIGOTSKI, 2007, p. 513, tradução nossa).

Ao sintetizar sua concepção sobre a relação entre pensamento e fala, Vigotski (2001, p. 484) afirma que a palavra é "absolutamente indispensável aos nossos pensamentos”. E consoante à sua visão dialética, histórica e processual sobre o desenvolvimento humano, ele expõe: "Mas o vínculo entre o pensamento e a palavra não é um vínculo primário, dado de uma vez por todas. Surge no desenvolvimento e ele mesmo se desenvolve" (VIGOTSKI, 2001, p. 484).

\footnotetext{
${ }^{6}$ Capítulo "Pensamiento y palabra" do livro "Pensamiento y habla" (VIGOTSKI, 2007).

7 Segundo a tradução argentina, trata-se de um trecho do poema "A andorinha" do poeta russo Ossip Mandelstam, perseguido por Stálin.
} 
Assim, sendo o conceito uma ação do pensamento e tendo a palavra um destacado papel em seu desenvolvimento, importante destacar também que a relação entre pensamento e fala é um processo que se dá ao longo do percurso do desenvolvimento e que a própria relação, ela mesma, se desenvolve. É uma relação que, assim como todo o desenvolvimento humano, tem uma história tanto filogenética, isto é, na história da humanidade, quanto ontogenética, ou seja, na história de cada ser humano. Ao discutir o desenvolvimento dos conceitos na infância, o autor nos diz:

[...] quando se assimila uma nova palavra, o processo de desenvolvimento do conceito correspondente não se finaliza, mas está apenas começando. Quando se assimila pela primeira vez uma palavra nova, essa não se situa no final, mas no começo de seu desenvolvimento, e sempre é neste período uma palavra imatura. $\mathrm{O}$ paulatino desenvolvimento interno de seu significado leva também à maturação da própria palavra. $\mathrm{O}$ desenvolvimento do aspecto semântico da fala é aqui, como em todas as partes, o processo fundamental e decisivo no desenvolvimento do pensamento e da fala da criança (VIGOTSKI, 2007, p. 422, tradução nossa).

Nessa direção, de acordo com Vigotski, quando uma criança aprende uma palavra, este aprendizado está apenas se iniciando, sendo o desenvolvimento do aspecto semântico, ou seja, aquele relativo ao significado, a questão central para o desenvolvimento do pensamento e da fala. Isto é, na relação entre pensamento e fala, o significado é fundamental.

O significado da palavra é, para Vigotski (2001), o que une pensamento e fala, é a unidade indecomponível dessa relação. Assim como Marx, em sua investigação, chegou até a mercadoria como unidade de análise da sociedade capitalista, Vigotski propôs o significado da palavra como unidade indecomponível entre pensamento e fala. Isso porque ele é, ao mesmo tempo, um fenômeno intelectual (do pensamento) e discursivo (da fala). O significado da palavra é um fenômeno do pensamento pois é uma ideia, um conceito que está relacionado à palavra e nela materializado. E é um fenômeno da fala porque é um som vinculado ao pensamento, um som que possui significado e, por isso, se distingue de todos os outros sons da natureza. O significado da palavra é a palavra vista do seu interior (VIGOTSKI, 2001). 
Contudo, segundo Vigotski (2001), para a compreensão de uma palavra, não basta o significado. É preciso que se considere também o sentido. De acordo com o autor, o sentido da palavra varia conforme o contexto da frase (ou contexto "gramatical") e o contexto psicológico interior, sendo a soma de todos os fatos psicológicos que ela desperta na consciência. Assim, o sentido é dinâmico, fluido, complexo, possuindo várias zonas de estabilidade. E o significado constitui uma dessas zonas que é mais estável, uniforme e exata. Vigotski (2007, p. 494, tradução nossa) afirma que a palavra muda facilmente de sentido conforme o contexto, ao passo que o significado é um ponto imóvel, imutável, permanecendo estável nas mudanças de sentido da palavra em diferentes contextos: "A palavra isolada, tomada do dicionário, possui apenas um significado. Mas este significado não é mais do que uma potencialidade que se realiza na fala viva, na qual o significado é somente uma pedra a mais no edifício do sentido”.

Para exemplificar essa discussão, Vigotski (2001) cita a fábula “A libélula e a formiga”, do autor russo Krilov. Segundo Vigotski, a palavra com que o autor termina seu texto - dance - possui um significado bastante definido. No entanto, considerando o contexto da fábula, tal palavra adquire um sentido intelectual e afetivo bem mais amplo, significando simultaneamente "divirta-se e morra". E acrescenta:

Esse enriquecimento das palavras que o sentido lhes confere a partir do contexto é a lei fundamental da dinâmica do significado das palavras. A palavra incorpora, absorve de todo o contexto com que está entrelaçada os conteúdos intelectuais e afetivos e começa a significar mais e menos do que contém o seu significado quando a tomamos isoladamente e fora do contexto... (VIGOTSKI, 2001, p. 466).

O autor continua a sua explicação acerca do sentido dizendo que a palavra só adquire sentido na frase, a frase adquire sentido no parágrafo, o parágrafo no contexto do livro e o livro, por sua vez, no contexto de toda a obra de um autor, num sistema de relações. Diz Vigotski (2007, p. 495, tradução nossa): "O verdadeiro sentido de cada palavra se define, em última instância, por toda a abundância de aspectos existentes na consciência relativos ao expresso por tal palavra”. E completa com uma citação do filósofo francês 
Frédéric Paulhan (apud VIGOTSKI, 2007, p. 495, tradução nossa) ${ }^{8}$, de quem Vigotski tomou emprestada a distinção entre sentido e significado da palavra ${ }^{9}$ : "A palavra é uma fonte inesgotável de novos problemas. O sentido de uma palavra nunca está acabado. Em última instância, se apoia na concepção de mundo e na estrutura interna da pessoa em seu conjunto".

Vigotski discute a questão do sentido no tocante à palavra. Não obstante a riqueza trazida pelo conceito de sentido ao encerrar em si uma possibilidade de superação da cisão razão-emoção, cognição-afeto (GÓES; CRUZ, 2006), representando um "divisor de águas" na obra de Vigotski (2001), ele foi pouco desenvolvido pelo autor.

Leontiev (1978) discute o conceito de sentido a partir da atividade humana, aprofundando essa dimensão. Esse autor introduz a adjetivação social e pessoal, respectivamente, aos conceitos vigotskianos de significado e sentido, e entende que o significado social e o sentido pessoal constituem, ao lado do conteúdo sensível, a consciência humana. E para descobrir as características da consciência, Leontiev (1978, p. 98) postula que:

[...] devemos estudar como a consciência do homem depende do seu modo de vida humano, da sua existência. Isto significa que devemos estudar como se formam as relações vitais do homem em tais ou tais condições sociais históricas e que estrutura particular engendra dadas relações. Devemos em seguida estudar como a estrutura da consciência do homem se transforma com a estrutura da sua atividade.

Segundo o autor, o sentido pessoal é constituído no decorrer da atividade do sujeito. E a forma pela qual o indivíduo se apropria (ou não) de determinados significados sociais depende da relação de interesse deste indivíduo com tais significados, ou seja, depende do sentido pessoal que elas apresentam para o sujeito. Nesse aspecto, Leontiev (1978, p. 104) estabelece a importância do motivo para a constituição do sentido pessoal: “[...] para encontrar o sentido pessoal devemos

\footnotetext{
8 Vigotski não menciona a qual obra de Paulhan está se referindo. Rochex (1995) afirma que se trata de um texto de 1929 denominado "La double fonction du langage" (A dupla função da linguagem).

9 Segundo Toassa (2009), conforme informações obtidas pela autora com Kellogg, o artigo de Paulhan seria "Qu'est-ce que le sens des mots?" (Qual o sentido das palavras?). Mas, as verdadeiras fontes de Vigotski quanto a essa questão teriam sido Voloshinov e Mandelstam, já que, segundo a autora e Kellogg, no pensamento de Paulhan, haveria aspectos incompatíveis com a concepção vigotskiana. Todavia Vigotski teria sido impedido de citar tais autores em função da censura.
} 
descobrir o motivo que lhe corresponde"10. O conceito de motivo, contudo, não pode ser entendido como tradução de uma necessidade puramente individual ou meramente psicológica (LEONTIEV, 1978, p. 103), ou, em outros termos, como o sentimento de uma necessidade. O autor utiliza-o para designar aquilo em que a necessidade se concretiza de forma objetiva e para a qual a atividade do sujeito se orienta. Leontiev (1978, p. 104) dá como exemplo a seguinte situação:

Imaginemos um aluno lendo uma obra científica que lhe foi recomendada. Eis um processo consciente que visa um objetivo preciso. O seu fim consciente é assimilar o conteúdo da obra. Mas qual é o sentido particular que toma para o aluno este fim e por consequência a ação que lhe corresponde? Isso depende do motivo que estimula a atividade realizada na ação da leitura. Se o motivo consiste em preparar o leitor para a sua futura profissão, a leitura terá um sentido. Se, em contrapartida, se trata para o leitor de passar nos exames, que não passam de uma simples formalidade, o sentido da sua leitura será outro, ele lerá a obra com outros olhos; assimilá-la-á de maneira diferente.

No exemplo dado por Leontiev, fica claro que, variando o motivo, também varia a atividade, embora a ação seja a mesma. O exemplo também traz a importância do sentido na apropriação de $\operatorname{algo}^{11}$.

A partir das discussões anteriormente feitas, entendemos, com Vigotski (2001) e Leontiev (1978), que a fala ou a língua é uma produção humana, originando-se sempre, assim como toda atividade humana, de uma necessidade. A fala é uma construção histórica e cultural humana que se desenvolveu da necessidade de comunicação advinda das relações sociais. E, ao se apropriar dela, cada indivíduo atualiza em si essa história, modificando-se e humanizando-se. Pois, assim como Marx afirma que o homem constrói instrumentos e, ao utilizálos, modifica-se a si próprio, Vigotski afirma o mesmo em relação à língua, sendo a palavra um instrumento de ordem simbólica. Nas palavras do autor:

Inicialmente, a fala para a criança consiste num meio de contato entre as pessoas, apresenta-se em sua função social, em seu papel social. Mas, pouco a pouco, a criança aprende a aplicar a fala para servir a si própria, aos seus processos internos. Logo, a fala já se

\footnotetext{
10 Rochex (1995) defende o uso da palavra francesa “mobile” (móvel) no lugar de motivo.

11 Para uma discussão mais aprofundada sobre a questão do sentido em Vigotski e Leontiev, sugerimos a consulta a Namura (2004), Asbahr (2014), Piotto; Asbahr; Furlanetto (2017) e Mendonça; Asbahr (2019).
} 
torna não apenas um meio de contato com as pessoas, mas também um meio de raciocínio interior à própria criança. Então, isso já não será aquela fala que pode ser ouvida, que nós empregamos quando nos dirigimos uns aos outros, mas será uma fala interior, calada, muda. Mas, enquanto um meio de raciocínio, a fala surgiu a partir de quê? Da fala enquanto um meio de contato. Da ação exterior que se dava entre a criança e as pessoas ao redor, surgia uma das mais importantes funções interiores, sem as quais o raciocínio da própria pessoa seria impossível (VIGOTSKI, 2010, p. 699, grifos do autor).

Além disso, para Vigotski (2001), toda palavra é sempre uma generalização. Assim, apenas a título de ilustração e num exemplo bastante simples, a palavra /CADEIRA/ é uma generalização de muitas e variadas cadeiras. Significa algo que serve para sentar, mas não se refere especificamente a uma determinada cadeira, ou seja, é uma palavra que nomeia uma classe de objetos, mas não se refere a algum objeto específico com apenas certas características, e sim a uma ideia. Quando alguém fala /CADEIRA/ está se referindo a uma ideia geral de cadeira, ou seja, a um conceito.

É isso o que a criança vai apreendendo ao ir se apropriando da fala. Contudo, como vimos anteriormente, o processo de formação dos conceitos é algo longo e bastante complexo. Vigotski dedicou-se ao seu estudo, analisando detalhadamente seu desenvolvimento ao investigar o pensamento sincrético, o pensamento por complexos e, finalmente, o pensamento conceitual. Não poderemos, aqui, nos ocupar dessa discussão com a profundidade que ela requer. No entanto, importa assinalar que, segundo Vigotski (2010), na criança, o processo de apropriação da fala é diferente do que ocorre com os adultos.

Isso porque a criança, ao falar, embora relacione as palavras com os mesmos objetos que os adultos, elas o fazem de outra maneira. Não obstante a criança, ao falar, também opere com generalizações, já que toda palavra é um conceito, essas são de outro tipo, isto é, são realizadas com a ajuda de outra ação mental. Segundo Vigotski (2010), a generalização nas crianças possui um caráter mais concreto, mais evidente, mais visual ou mais factual. Para explicar essa diferença, Vigotski (2010) dá como exemplo a identificação da filiação por meio dos sobrenomes. Assim como nós sabemos que um sobrenome se refere a um grupo de pessoas, mas só conseguimos defini-lo por meio de uma filiação autêntica, real, ou seja, com base no parentesco legítimo, real existente entre as 
pessoas, também as crianças generalizam diversos objetos por meio da palavra, mas as relações entre eles são concretas, reais, e não relações lógicas.

Após apresentarmos a relação entre pensamento e palavra, consideramos importante, ainda que de forma breve, conhecer a visão de Vigotski sobre a relação entre palavra e ação. Citando a frase do Evangelho, "No princípio era o Verbo", e a contraposição de Goethe, "No princípio era a ação", o autor afirma:

Mas, observa Humboldt, mesmo se com Goethe não colocarmos demasiado alto a palavra como tal, isto é, a palavra sonora, e com ele traduzirmos o verso bíblico "No princípio era o Verbo", poderemos lê-lo com outro acento se o abordarmos do ponto de vista da história do desenvolvimento. No princípio era a ação. Com isso ele quer dizer que a palavra lhe parece o estágio supremo do desenvolvimento do homem comparada à mais suprema expressão da ação. É claro que ele tem razão. A palavra não esteve no princípio. No princípio esteve a ação. A palavra constitui antes o fim que o princípio do desenvolvimento. A palavra é o fim que coroa a ação (VIGOTSKI, 2007, p. 514, tradução nossa, grifo do autor).

Ou seja, se Vigotski aborda primordialmente a questão da fala, em especial no final de sua obra, que foi interrompida pela morte precoce aos 38 anos de idade, isso não significa que ele a entenda como desvinculada da ação humana. Ao contrário, como expresso na citação, a palavra é, em última instância, uma ação que foi coroada por ela.

Por fim, entendemos que a discussão sobre a formação dos conceitos está relacionada à discussão sobre a questão da fala e sua relação com o pensamento. Não por acaso Vigotski (2007) dedicou os três últimos capítulos daquela que é considerada sua mais importante obra ("Pensamento e fala") à discussão das relações entre essas questões, abordando o estudo do desenvolvimento dos conceitos científicos e finalizando com a discussão sobre a relação entre pensamento e palavra (VIGOTSKI, 2007).

\section{Considerações finais}

O objetivo deste artigo foi discutir algumas bases vigotskianas que apoiam teórica e metodologicamente a Atividade Orientadora de Ensino. Para isso, apresentamos brevemente essa Atividade e, na sequência, discutimos algumas 
ideias de Vigotski que lhe servem de base, especialmente a questão da formação de conceitos e a relação entre pensamento e fala.

A Atividade Orientadora de Ensino é um modo geral de organização da atividade pedagógica que (re)produz, sintética e essencialmente, uma necessidade real vivida pelo ser humano em sua história e que redundou na produção de um determinado conceito para assim criar as condições para que estudantes também possam apropriar-se dessa produção cultural. Por meio das situações desencadeadoras de aprendizagem, o professor, ao organizar o ensino segundo os princípios teóricos e metodológicos da AOE, coloca o aluno diante de um problema com o qual o ser humano também se deparou ao longo de seu processo histórico e para o que foi preciso desenvolver uma forma de resolvê-lo: um conceito.

Em síntese é isso o que Vigotski afirma a respeito da formação e da apropriação dos conceitos. Segundo o autor, o conceito forma-se apenas a partir da necessidade de se resolver um problema. Isto é, de acordo com Vigotski (2007), o conceito é uma ação do pensamento e atende sempre a uma necessidade, possuindo uma função. Além disso, ele apenas pode se formar como resposta a uma necessidade concreta.

Também é possível relacionar a Atividade Orientadora de Ensino com o processo por meio do qual os seres humanos apropriam-se da maior produção cultural histórica da humanidade - a fala.

A partir da relação entre a formação de conceitos e o desenvolvimento do pensamento e da fala proposta por Vigotski (2001), compreendemos que, assim como a criança aprende a falar estando colocada em uma situação sintética e essencialmente análoga àquela vivida pelo ser humano em sua história, isto é, movida pela necessidade de se comunicar, e em relação com outros que já se apropriaram da fala, produto de ação coletiva humana, também dessa forma dever-se-ia dar o processo de ensino-aprendizagem dos conceitos científicos.

E é isso o que a Atividade Orientadora de Ensino faz.

A AOE (re)produz intencional, sistemática e deliberadamente, em certo sentido, as condições de apropriação da fala em que as crianças estão inseridas e por meio das quais se apropriam dessa produção cultural humana. Contudo, a diferença entre estas duas situações residem no fato de que a aprendizagem da 
fala ocorre, em geral, por meio de um processo não-intencional e assistemático. Já o ensino de conceitos requer uma organização sistemática e intencional de ensino.

Em relação a este aspecto, é importante relembrar a crítica de Vigotski às investigações de Ach já aqui apresentada. O autor afirma que naquelas investigações havia o entendimento de que a resposta à situação apresentada estaria dada na própria situação. Ou seja, o conceito estaria dado pela própria resolução do problema.

Neste ponto, necessário destacar que, assim como Vigotski, também a Atividade Orientadora de Ensino entende que nenhuma situação desencadeadora de aprendizagem, quer seja uma história virtual ou um jogo, contém, em si mesma, o conceito que se pretende ensinar. O conceito, sendo uma ação do pensamento, não está dado em nenhuma situação, mas sim deve estar apropriado por aquele que organiza uma atividade com a finalidade explícita, específica e intencional de promover a aprendizagem dele por alguém. Em plena consonância com a Teoria Históricocultural, o professor é figura central e absolutamente imprescindível para a AOE. É ele quem, tendo se apropriado do conceito e modificado-se, pode, em coletividade, organizar sua atividade de ensino de modo a mobilizar os estudantes para a apropriação do conceito por meio da recriação de uma necessidade que também moveu o ser humano em seu processo histórico de desenvolvimento. E assim fazendo permitir com que outros também se apropriem do conceito e modifiquem-se a si próprios.

A Atividade Orientadora de Ensino ao partir da forma com a qual o ser humano apreende as produções simbólicas da espécie, explicitando-a, permite o domínio da forma de aprender humana, e fornece os meios para que professores organizem a sua atividade de trabalho de modo a fazer com que seus alunos possam também apropriar-se dos conceitos científicos. Esse domínio do modo de aprender humano faz com que se possa deliberada, sistemática e intencionalmente utilizar esta forma para ensinar e promover a aprendizagem de conceitos. Esse domínio promovido pela Atividade Orientadora de Ensino permite também contrapor-se ao modo mais comum de educação escolar que se baseia, principalmente, em ideias associacionistas sendo guiado por um verbalismo que pressupõe que aprender um conceito resume-se a repetir palavras. Contra isso, e baseada em Vigotski, a AOE entende que o conceito é uma ação do pensamento que se originou da atividade humana em seu processo histórico de desenvolvimento para atender a uma 
necessidade e propõe a recriação dessa situação para que outros seres humanos possam ter assegurado o direito de apropriarem-se de produções simbólicas de sua espécie. Assim, por exemplo, o fato de uma criança saber falar os números de um a dez não significa em absoluto que ela entenda o sistema de numeração decimal. Como vimos, Vigotski é enfático ao dizer que quando a criança aprende uma palavra nova a aprendizagem dela e do conceito correspondente está apenas começando. Para que ela se aproprie daquele sistema é preciso que seja mobilizada por uma situação análoga à vivida pela humanidade que tornou necessário o desenvolvimento desse sistema conceitual e que seu pensamento esteja em movimento. Foi isso o que vimos ter sido iniciado e desenvolvido a partir da situação desencadeadora de aprendizagem "A viagem de Ulisses" organizada a partir dos pressupostos teóricos e metodológicos da Atividade Orientadora de Ensino e discutida aqui anteriormente.

Talvez resida aí a razão pela qual esse modo geral de organização de ensino venha demonstrando grande potencialidade educativa. Os relatos provenientes de professores e escolas que têm se valido da AOE para organizar a atividade pedagógica é a de que ela gera amplo e efetivo engajamento tanto por parte dos professores quanto dos estudantes. Conforme destacam Moura, Araújo e Serrão (2018), os relatos também dão conta de que crianças consideradas "problema" na escola participam ativamente das atividades organizadas segundo os princípios teórico-metodológicos da Atividade Orientadora de Ensino.

A partir da Teoria Histórico-cultural, entendemos que crianças que conseguiram se apropriar da maior produção humana tem todas as condições de também se apropriarem de outras riquezas simbólicas produzidas por essa mesma humanidade. E se não o fazem é porque, infelizmente, e por diversas razões, a forma como a educação escolar está organizada não permite isso.

Recriando sintética e essencialmente a forma como os seres humanos produziram conhecimento, a Atividade Orientadora de Ensino parece ser uma valiosa ferramenta a contribuir para que todos possam se apropriar da produção cultural humana, tornar suas essas riquezas simbólicas, transformando-se a si e assim podendo também transformar o mundo. 


\section{Referências}

ASBAHR, F. S. F. Sentido pessoal, significado social e atividade de estudo: uma revisão teórica. Psic. Esc. Ed., Maringá, vol. 18, n. 2, ago. 2014, p. 265-272. DOI: http://dx.doi.org/10.1590/2175-3539/2014/0182744.

LEONTIEV, Alexis N. O desenvolvimento do psiquismo. Lisboa: Horizonte Universitário, 1978.

MENDONÇA, A. B. J.; ASBAHR, F. DA S. F. Atividade de estudo e sentido pessoal: uma revisão teórica. Obutchénie: Revista de Didática e Psicologia Pedagógica, v. 2, n. 3, p. 780-800, 21 mar. 2019. DOI:

https://doi.org/10.14393/OBv2n3.a2018-47450.

MORAES, S. P. G.; LAZARETTI, L. M.; ARRAIS, L. F. L. Formar formando: o movimento de aprendizagem docente na Oficina Pedagógica de Matemática. Obutchénie: Revista de Didática e Psicologia Pedagógica, v. 2, n. 3, p. 643-668, 20 mar. 2019. DOI: https://doi.org/10.14393/OBv2n3.a2018-47439.

MOURA, M. O.; ARAUJO, E.; SERRÃO, M. I. Atividade Orientadora de Ensino: fundamentos. Linhas críticas. Vol 24, p. 411-430, 2018. DOI:

https://doi.org/10.26512/lc.v24i0.19817.

MOURA, M.O.; ARAÚJO, E. S. A atividade orientadora de ensino como mediação. In: BEATÓN, G. A. et al. (orgs). Temas escolhidos na Psicologia histórico-cultural: interfaces Brasil-Cuba. Vol. II. Maringá: Eduem, 2018, p. 193 - 213.

MOURA, M. O.; SFORNI, M. S.F.; LOPES, A. R. L. V. A objetivação do ensino e o desenvolvimento do modo geral da aprendizagem da atividade pedagógica. In: MOURA, M. O. (org.) Educação escolar e pesquisa na Teoria Histórico-cultural. São Paulo: Edições Loyola, 2017, p. 71 - 99.

MOURA, M. O. et al. A atividade orientadora de ensino como unidade entre ensino e aprendizagem. In: MOURA, M. O. A atividade pedagógica na Teoria Histórico-cultural. Brasília: Liber livro, 2010, p. 81-109.

MOURA, M. O. A construção do signo numérico em situação de ensino. 1992. Tese (Doutorado em Educação) - Universidade de São Paulo, SP, 1992.

MUNHOZ, A. P. G. et al. Formação do pensamento teórico no processo de organização do ensino na perspectiva histórico-cultural. (no prelo).

NAMURA, Maria Regina. Por que Vygotsky se centra no sentido: uma breve incursão pela história do sentido na psicologia. Psicologia da Educação, São Paulo, v. 19, p. 91-117, 2004.

NASCIMENTO, C. P. Uma Educação Física Histórico-Cultural (?) Os significados das atividades da cultura corporal como uma problemática geral de pesquisa para a área. Obutchénie: Revista de Didática e Psicologia Pedagógica, v. 2, n. 2, p. 339363, 22 dez. 2018. DOI: https://doi.org/10.14393/OBv2n2a2018-3. 
PANOSSIAN, M. L. et al. A oficina pedagógica de matemática como atividade. Obutchénie: Revista de Didática e Psicologia Pedagógica, v. 1, n. 4, p. 14-39, 23 maio 2018. DOI: https://doi.org/10.14393/OBv2n1a2018-2.

PIOTTO, D. C.; ASBAHR, F. S. F.; FURLANETTO, F. R. Significação e sentido na psicologia histórico-cultural: implicações para a educação escolar. In: MOURA, M. O. (Org.). Educação escolar e pesquisa na Teoria Histórico-cultural. São Paulo: Edições Loyola, 2017, p. 101-123.

PRESTES, Zoia; TUNES, Elizabeth. A trajetória de obras de Vigotski: um longo percurso até os originais. Estud. psicol. (Campinas), Campinas, v. 29, n. 3, p. 327 340, Setembro. 2012. DOI: http://dx.doi.org/10.1590/S0103-166X2012000300003.

ROCHEX, Jean-Yves. Le sens de l'experience scolaire. Paris: PUF, 1995.

ROSA, J. E.; MATOS, C. F. Atividade orientadora de ensino e proposição davydoviana na organização do ensino de matemática. Obutchénie: Revista de Didática e Psicologia Pedagógica, v. 1, n. 4, p. 69-91, 23 maio 2018. DOI: https://doi.org/10.14393/OBv2n1a2018-4.

ROSA, J. E; MORAES, S. P. G.; CEDRO. W. L. A formação do pensamento teórico em uma atividade de ensino de matemática. In: MOURA, M. O. A atividade pedagógica na Teoria Histórico-cultural. Brasília: Liber livro, 2010, p. 135-153.

TOASSA, G. "Atrás da consciência, está a vida": o afastamento teórico LeontievVigotski na dinâmica dos círculos vigotskianos. Educ. Soc., Campinas, v. 37, nº 135, p.445-462, abr.-jun., 2016.

VIGOTSKI, L. S. Sete aulas de L. S. Vigotski sobre os fundamentos da pedologia. Tradução e organização: Zoia Prestes, Elisabeth Tunes. RJ: E-papers, 2018.

VIGOTSKI, L. S. O problema do ambiente na Pedologia. In: LONGAREZI, A. M.; PUENTE, R. V. (orgs). Ensino desenvolvimental: antologia. Livro 1. Uberlândia: EDUFU, 2017.

VIGOTSKI, L. S. Quarta aula: a questão do meio na pedologia. Trad. Marcia Pileggi Vinha. Psicologia USP, São Paulo, v. 21, n. 4, p. 681-701, 2010.

VIGOTSKI, L. S. Pensamiento y Habla. Buenos Aires: Colihue, 2007.

VIGOTSKI, L. S. A construção do pensamento e da linguagem. SP: Martins Fontes, 2001. 